\title{
POSTBUCKLING BEHAVIOUR OF LAMINATED PLATES WITH A CUT-OUT
}

\author{
Katarzyna Falkowicz ${ }^{1}$, Hubert Dębski ${ }^{1}$ \\ 1 Faculty of Mechanical Engineering, Department of Machine Design and Mechatronics, Lublin University of \\ Technology, Nadbystrzycka 36, 20-618 Lublin, Poland, e-mail: k.falkowicz@pollub.pl, h.debski@pollub.pl
}

Received: 2016.12 .15

Accepted: 2017.02.01

Published: 2017.03.01

\begin{abstract}
The subject of research is the numerical and experimental analysis of a thin-walled plate with the cut-out, made of the laminate and subjected to the axial compression. In order to ensure the stable plate work in the postcritical range, it need to force its work by higher flexural-torsional form of buckling. The scope of the research included nonlinear numerical analysis with Finite Element Method (FEM) and experimental verification of calculation results. For the composite material in numerical calculations, the model of orthotropic material in the flat state of tension was defined. For the mapping of the plate element coating finite elements of type SHELL was applied with a shape function of the second order to allow the mapping of the composite structure for the element thickness. The experimental research was carried out in a special grips providing the articulated support of the upper and lower edges of the plate. The deformation registration of compression structures were carried out with resistance extensometry. This allowed to define of postcritical equilibrium paths of real structure, showing the dependence of the force to displacement. The instrument used was a numerical program ABAQUS ${ }^{\circledR}$.
\end{abstract}

Keywords: laminates, buckling, postbuckling, Finite Element Method.

\section{INTRODUCTION}

Continuous development of technology allows to disseminate known, but until recently, reserved mainly for leading industries (including the arms industry or aerospace), composite materials. The participation of composites in emerging structures is growing - these materials are increasingly displacing the traditional engineer materials (metals), where in addition to strength and durability, the important element is a relatively low weight of the structure. The composites are now very common in a variety of industries, such as: automotive, sports, medical (implants), and more and more designers reach for the lightweight materials in the design of building structures [23]. This constant dissemination of modern composite materials forces the researchers to develop increasingly simpler and more optimal tools for the design and production of these materials and to study the behavior of components made of composite materials subjected to different load states. One of the disadvantages of thin-walled composite bearing elements is the possibility of loss of stability in a certain load cases $[1,2,11,12,16$, $25 \div 29,10 \div 16]$. The uniform, thin plates belong to the group of structural elements relatively cheap to manufacture, but due to the low flexural stiffness they can transfer relatively small loads. When compressed, the loss of stability occurs at low load and has a flexural-torsional character. The known methods for improving the plates carrying capacity through the use of stiffeners or stamping, often lead to a significant change in the design, and sometimes can lead to disorderly growth of weight of the structure. However, there is a way to significantly improve the carrying capacity of this type of structure, even tempted to use this type of thin-walled structures, not only as a carrying capacity elements, but also as the elastic elements. 
The idea of improving the carrying capacity involves the forcing work of construction according to the higher form of buckling (flexural-torsional). To bring the plate to work in that form it is necessary to perform a central cut-out in the structure of the plate and initiate the movements of resulting vertical stripes in the opposite direction. In thus, the plate achieved the target form characterized by state work in the postcritical range. This creates the possibility of design plate elements with very favorable nonlinear-elastic characteristics, leading to a substantial increase the value of critical load and increase capacity of the structure. The issues of stability, critical behavior and limit load capacity of plate with holes are described, among others, in $[5,9,15,18,19,21,24]$.

The subject of contemplated in the present work are a rectangular plates with a central cutout, made of fiber composites with different layout of laminate layers. The scope of the research included the linear and nonlinear issue of stability the plate's composite structures subjected to uniform compression. The study was carried out with using a variety of research methods, combining the issues related to the experimental studies carried out on real composite structures and numerical calculations with using the finite element method. As a numerical tool a commercial package calculation - ABAQUS ${ }^{\circledR}$ program was used.

\section{RESEARCH METHODOLOGY}

In preliminary analyzes of the discussed issues, the subject of research were rectangular plates with cut-outs with variable geometrical pa- rameters, made of fiber composites with different layers of the laminate layout [5-8]. The scope of the research included issues of linear and nonlinear stability of plate structures with initiated geometric imperfection corresponding to the flexuraltorsional buckling form of structures, subjected to uniform compression. The studies were performed in the field of numerical simulation using FEM and verifying the results by experiments.

The results of the studies to date have shown that the classical FEM approach to the analysis of the post critical state with implemented higher form of buckling for plate with cut-out with [0/-45/45/90] $\mathrm{s}$ laminate layers layout, is incompatible with the real behavior of the structure. It failed to obtain a stable, higher, flexural-torsional form of buckling, due to the obtained in experiment plate's jump to a)

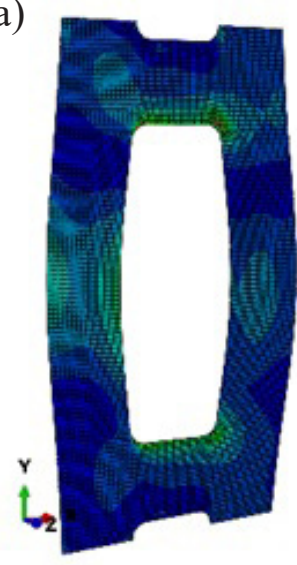

b)

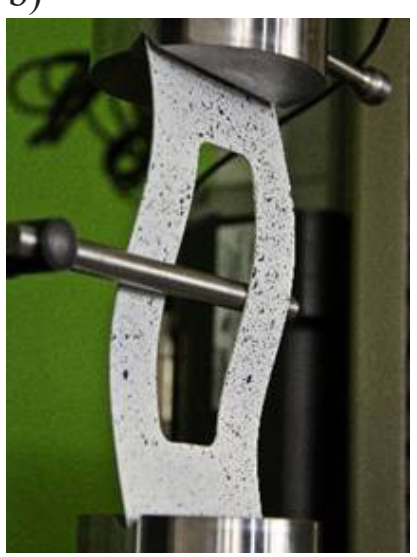

Fig. 1. Higher, flexural-torsional form of plate with cut-out loss of stability in the arrangement of [0/-45/45/90]s composite layers:

a) FEM calculations - stable form, b) experimental research- unstable form (jump phenomenon)

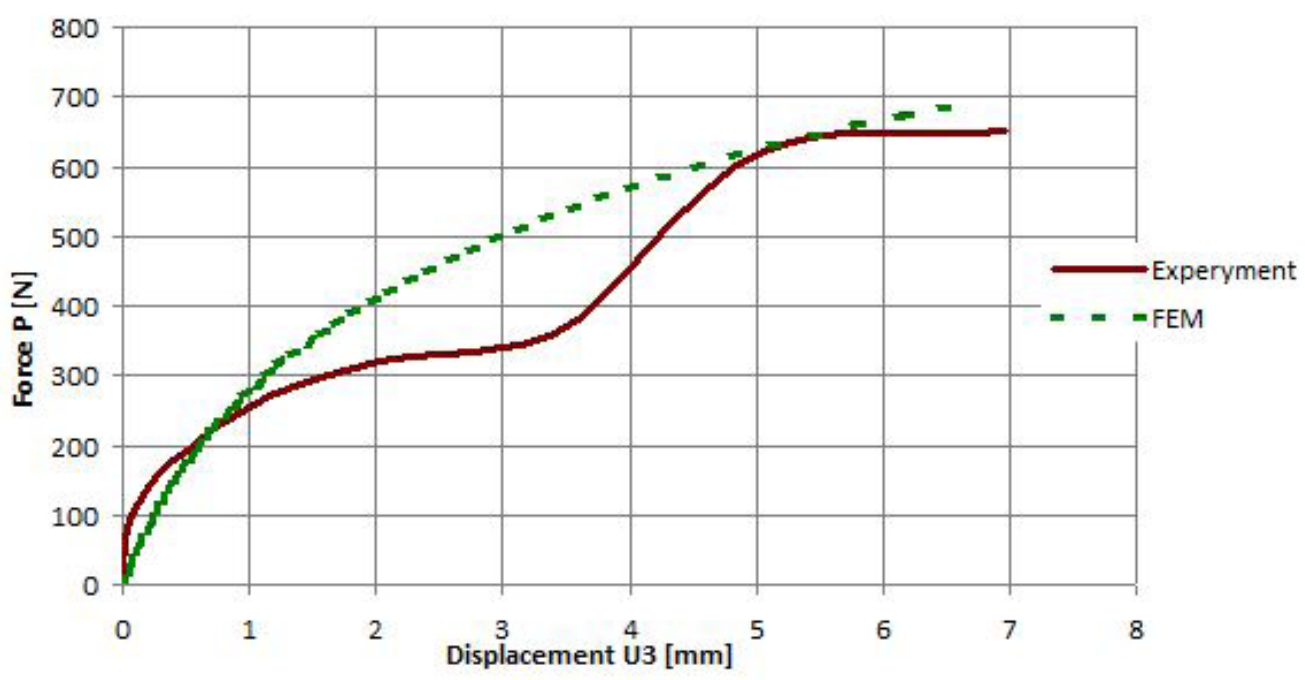

Fig. 2. Comparison of post-buckling paths appointed with FEM and experiment 
the lower form, which was not observed in numerical analysis (Fig. 1 and Fig. 2). The received jump phenomenon in the physical model occurs due to a difference in internal energy levels of structure between the lowest and assumed higher form of buckling, which was on the level of $411 \%$.

In order to eliminate the phenomenon of the jump in the real structure it was decided to find a method of obtaining the flexural-torsional form as a natural lowest form of buckling. Concept of anty-symmetrical reinforcement of plate surface, by sticking two isotropic strips, near of external vertical edge of plate, one on each side was developed.

\section{Subject of study}

The specimen was a rectangular plate with dimensions: $\mathrm{A} \times \mathrm{B}=160 \times 80 \mathrm{~mm}$ and thickness $\mathrm{g}=1.048 \mathrm{~mm}$, weakened by a central cut-out, wherein vertical edges stiffened by strips, made of isotropic material (Fig. 3). The plate was made of carbon-epoxy composite with 8 layers of the same thickness equal $0.131 \mathrm{~mm}$ in a symmetrical arrangement of layers relative to the central plane of package. The researches were carried out on composite plates made in the following configurations: [0/-45/45/90]s, [45/-45/90/0]s, [90/-45/45/0]s. Sticked stiffeners had a form of stripes made of aluminum. In numerical calculations a model of orthotropic material in the flat state of tension was defined. In order to determine the strength of the composite used the tensor failure criterion - Tsai-Wu, dedicated for composite materials. The geometrically nonlinear problem was solved by the Newton-Raphson method $[8,22 \div 25,27,28]$. Mechanical properties of the carbon-epoxy laminate used in the tests were collected in Table 1.

For modeling the composite structure and stiffening stripes shell finite elements were applied having six degrees of freedom in the element node. The used type of the element with the designation of S8R, accounted the element of the second row, with reduced integration, in the area of a)

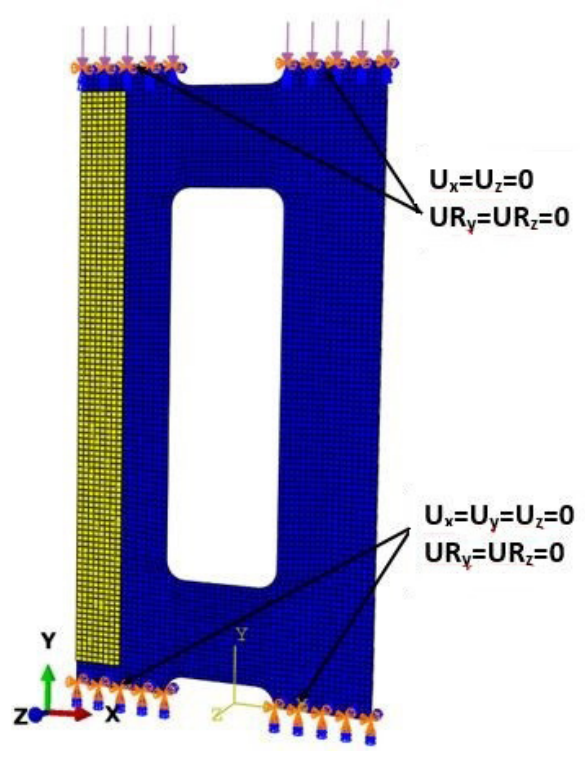

b)

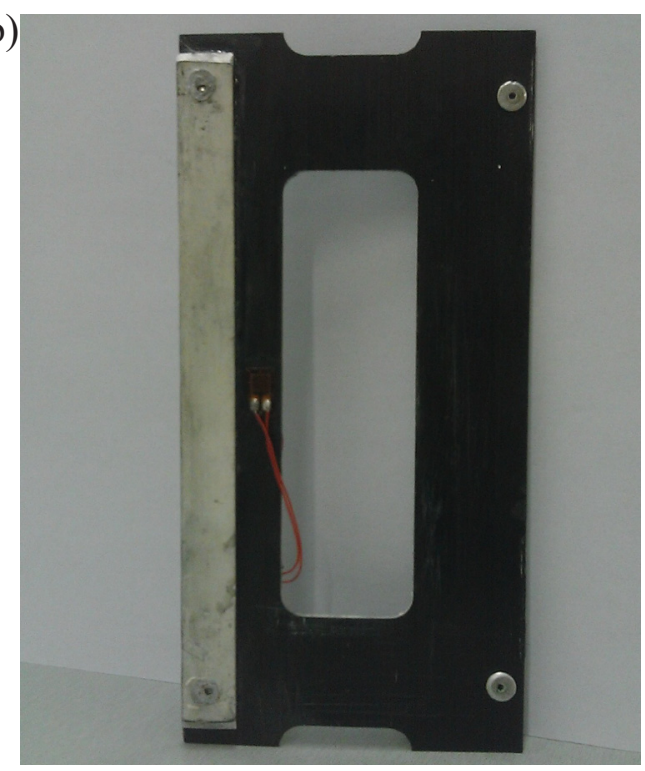

Fig. 3. Model of the tested composite plate with stripes a) numerical model with boundary conditions, b) real model

which through of the thickness, defined the structure of the arrangement of the individual laminate layers. The used type of finite element allows the construction of macroscopic models of discrete

Table 1. Mechanical properties of the carbon-epoxy laminate used in the tests

\begin{tabular}{|c|c|c|c|c|c|c|c|c|}
\hline \multirow{2}{*}{\multicolumn{2}{|c|}{$\begin{array}{c}\text { Tensile } \\
\text { Strength } \\
\text { [MPa] }\end{array}$}} & \multicolumn{2}{|c|}{$\begin{array}{l}\text { Young Modulus } \\
\text { [MPa] }\end{array}$} & \multirow{3}{*}{$\begin{array}{c}\begin{array}{c}\text { Poisson Ratio } \\
{[-]}\end{array} \\
v_{12} \\
0^{\circ}\end{array}$} & \multirow{3}{*}{$\begin{array}{c}\begin{array}{c}\text { Shearing } \\
\text { Strength } \\
\text { [MPa] }\end{array} \\
\mathrm{F}_{\mathrm{SU}} \\
\pm 45^{\circ}\end{array}$} & \multirow{3}{*}{$\begin{array}{c}\begin{array}{c}\text { Shear Modulus } \\
\text { [MPa] }\end{array} \\
\mathrm{G}_{12} \\
\pm 45^{\circ}\end{array}$} & \multirow{2}{*}{\multicolumn{2}{|c|}{$\begin{array}{c}\begin{array}{c}\text { Compressive } \\
\text { Strength } \\
\text { [MPa] }\end{array} \\
\mathrm{F}_{\mathrm{CU}} \\
\end{array}$}} \\
\hline & & \multirow{2}{*}{$\frac{E_{1}}{0^{\circ}}$} & \multirow{2}{*}{$\frac{\mathrm{E}_{2}}{90^{\circ}}$} & & & & & \\
\hline $0^{\circ}$ & $90^{\circ}$ & & & & & & $0^{\circ}$ & $90^{\circ}$ \\
\hline 1870 & 26 & 131710 & 6360 & 0.32 & 100.15 & 4180 & 1531 & 214 \\
\hline
\end{tabular}


thin-walled composite structures, using the model of orthotropic material in a flat state of tension. In the process of discretization the structural finite element mesh, based on the 8-node elements was used, thus ensuring the uniform plate division on finite elements. Dimension of a side single element was equal $1.43 \mathrm{~mm}$, which consequently led to obtain a discrete model compound of $6228 \mathrm{fi}-$ nite elements of the second row.

The defined boundary conditions of discrete model corresponded to realization of tests in the conducted experimental studies. The articulated support for the upper and lower edge of plate by blocking the translational and rotational degrees of freedom $\mathrm{U}_{\mathrm{x}}=\mathrm{U}_{\mathrm{y}}=\mathrm{U}_{\mathrm{z}}=\mathrm{UR}_{\mathrm{y}}=\mathrm{UR}_{\mathrm{z}}=0$ on the lower edge and $U_{x}=U_{z}^{z}=U R_{y}=U_{z}^{z}=0$ on the top edge was defined. The load of model was realized by the uniform loading of the upper edge of the plate in the direction of Y-axis, providing the condition of a uniform displacement in the direction of the applied load of nodes located on the upper edge.

\section{Methodology}

The scope of the research included the FEM numerical analysis of linear and nonlinear stability issue, where the calculations were carried out on models with initiated geometric imperfection corresponding to the flexural-torsional form of

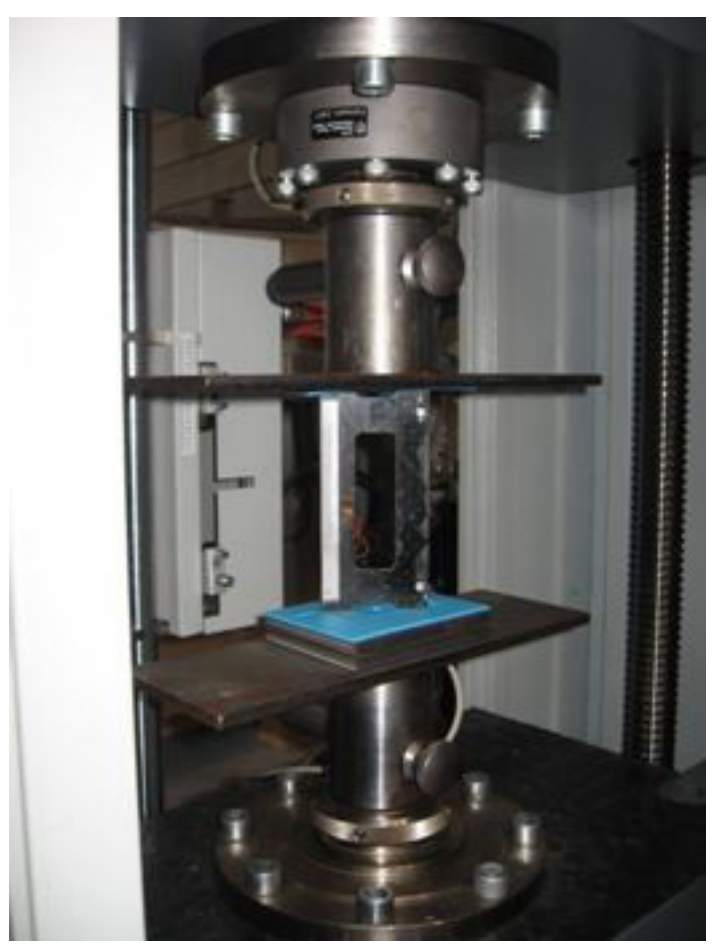

Fig. 4. Test stand structure buckling as well as experimental studies, which have enabled a verification of developed computational models.

The experimental tests were carried out on the Zwick Z100/SN3A universal testing machine (Fig. 4). The plate was supported articulately and loaded uniformly distributed compression force on the upper edge of the plate. All the tests were conducted in standard conditions, at $23^{\circ} \mathrm{C}$ with constant velocity of the cross-bar equal to $2 \mathrm{~mm} /$ min. For a proper description of the critical and postcritical state of construction, the displacement at selected points of the plate using the resistance extensometry was registered. During the measurements the following variables were additionally recorded: the duration of the measurement, compression force, cross-bar displacement and deflection of samples at selected points.

\section{RESULTS OF THE NUMERICAL CALCULATIONS AND THE EXPERIMENTAL INVESTIGATIONS}

The carried out researches showed that the used concept of plates with longitudinal reinforcements made of an isotropic material, arranged asymmetrically relative to the plane of plate, allows to obtain a natural, the lowest flexural-torsional buckling form, which showed the stable features during the loading process.

The critical buckling mode obtained from the experiment and FEM are compared in Figures 5-7. From both method the same mode have been obtained.

The above presented results show qualitative and quantitative convergence of critical load in numerical calculations with experimental results. The value of critical force appointed by these methods was fraught with error not exceeding $15 \%$. Figure 8 illustrates the influence of stiffeners in a form of strips on the value of the critical force.

As can be observed, the use of a new concept allows to increase the value of the critical force almost five times.

In the second stage of the calculation, constituting the solution of the nonlinear stability the plate work in postcritical state with forced the higher, flexural-torsional form of plate buckling was analyzed.

Post-critical equilibrium paths were also determined for the nodes experiencing maximal amplitudes of displacement. Figure 9 present the 
a)

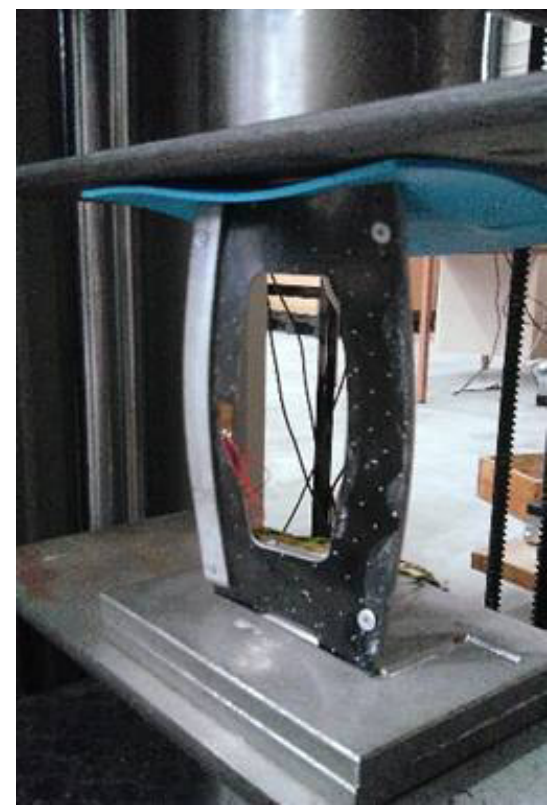

b)

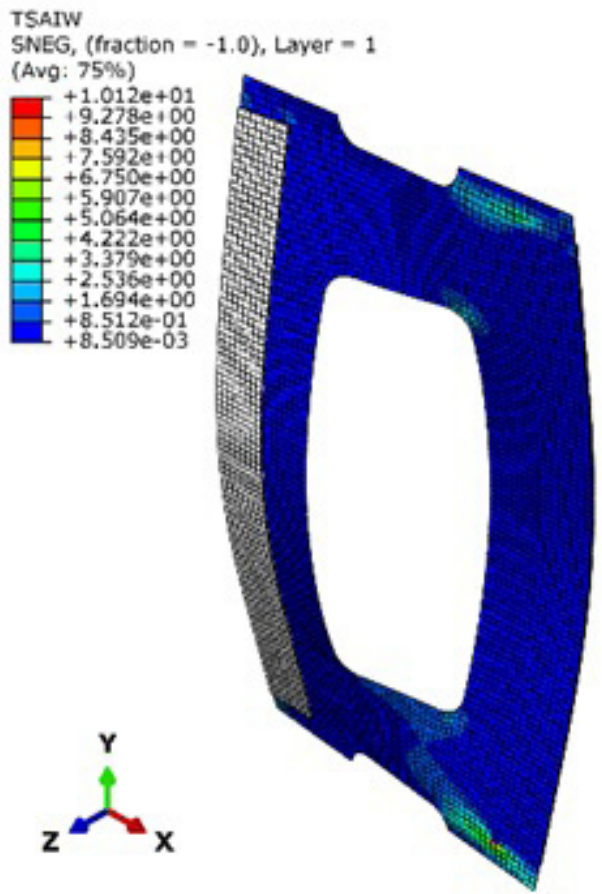

Fig. 5. Comparison of the a) experimental and b) numerical results.for $[90 /-45 / 45 / 0] \mathrm{s}$

results of experiments, as well as the FEM. The scope of the numerical simulations in post-critical range was done with the Tsai-Wu criterion.

The postcritical equilibrium paths designated in the experiment show lower rigidity than numerical calculations results, but the maximum differences do not exceed $16 \%$. This fact is related to higher rigidity of the numerical model, for which the ideal conditions of analysis are maintained, which is also consistent with the results of simi- a)

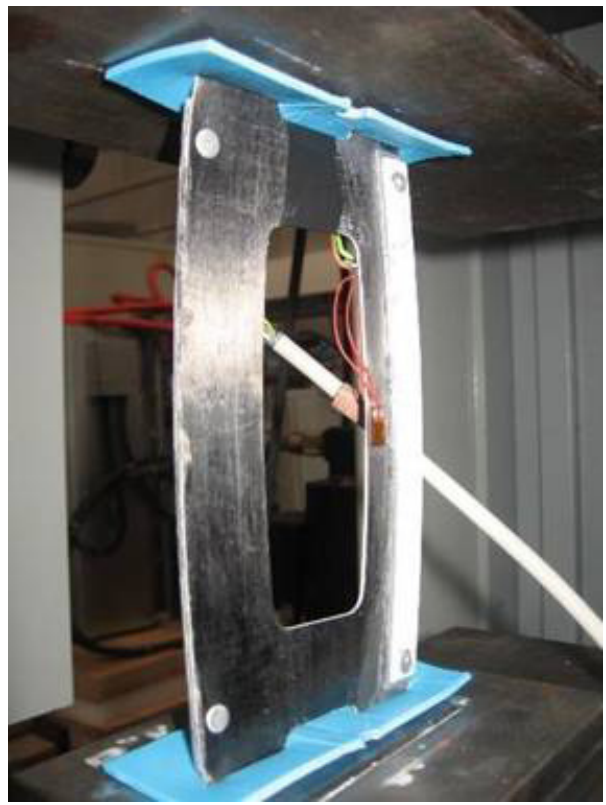

b) TSAIW SNEG, (fraction $=-1.0$ ), Layer $=1$ (Avg: $75 \%$ )

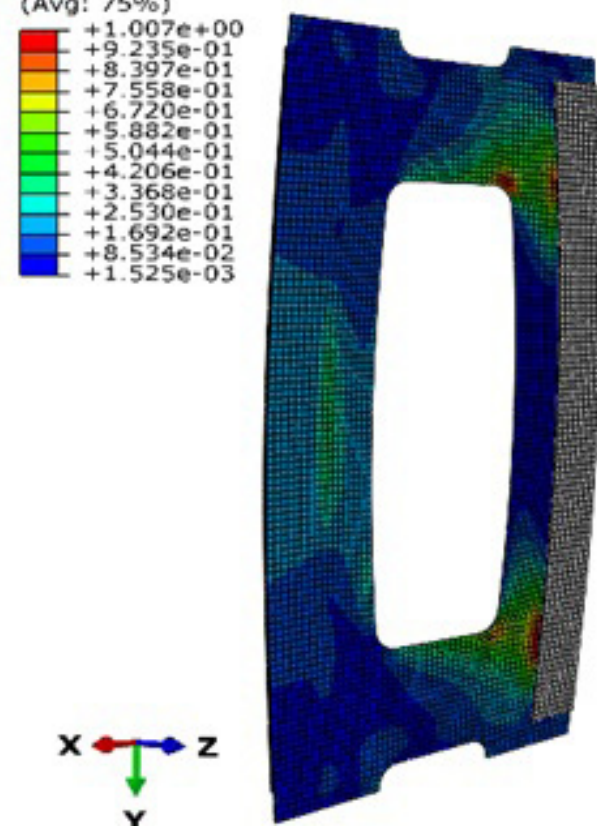

Fig. 6. Comparison of the a) experimental and b) numerical results.for $[0 /-45 / 45 / 0] \mathrm{s}$

lar studies published in the literature [2,3]. These conclusions have important practical meaning in the aspect of the calculation of that type structure for use as elastic elements.

\section{CONCLUSIONS}

In the presented study the analysis of thinwalled composite plates with cut-outs and with 

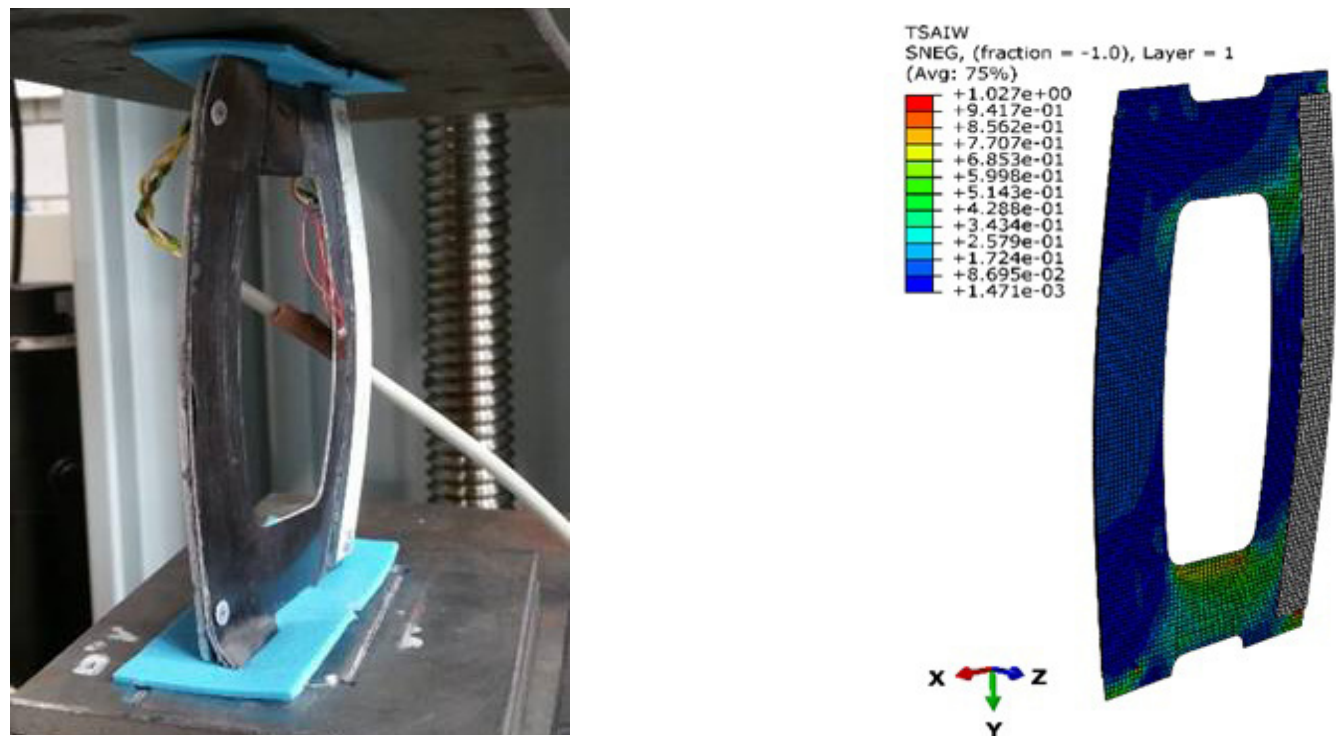

Fig. 7. Comparison of the a) experimental and b) numerical results for $[45 /-45 / 90 / 0] \mathrm{s}$

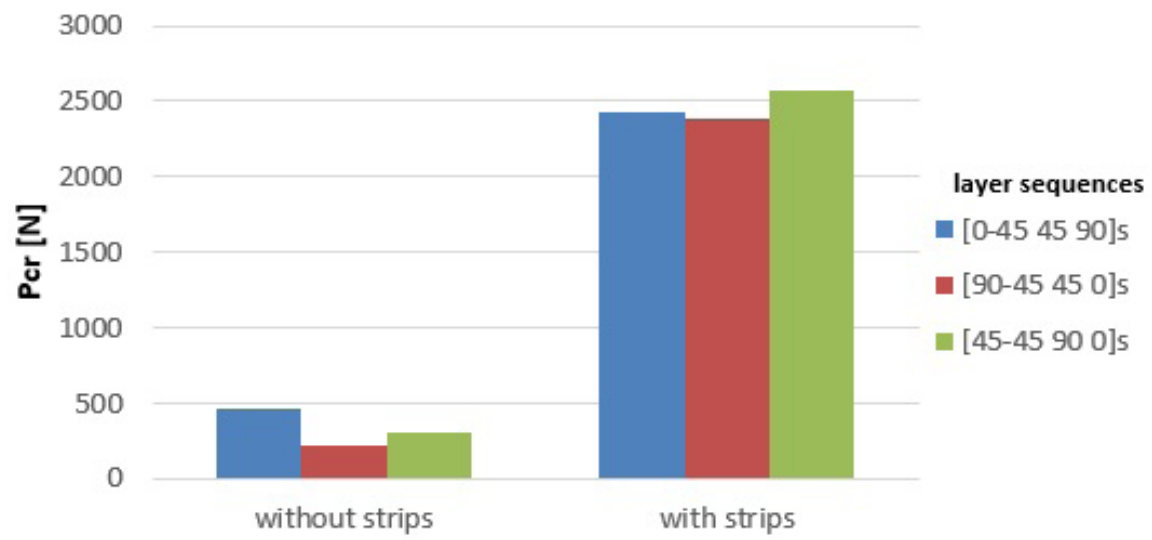

Fig. 8. The influence of stiffeners on the critical force

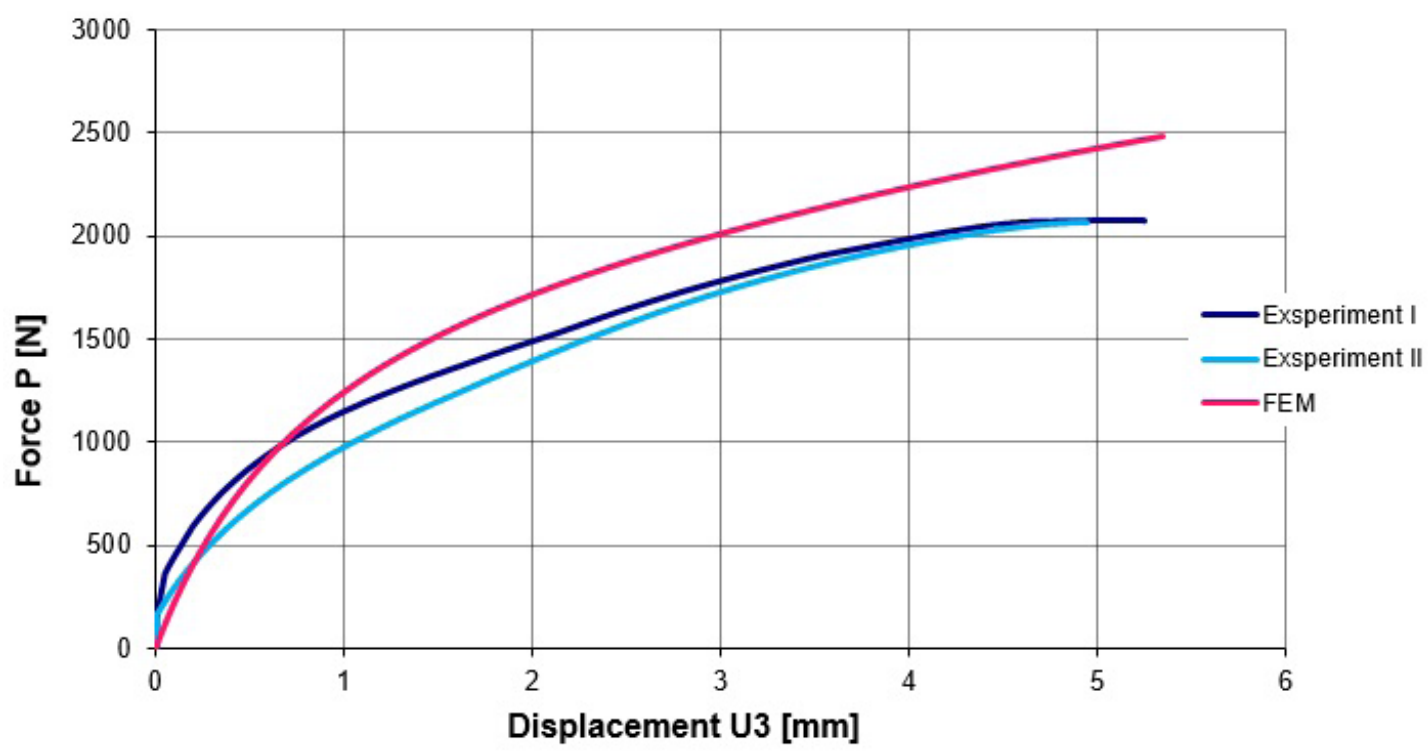

Fig. 9. Comparison of the experimental and numerical results for plate with $[90 /-45 / 45 / 0]$ s layer sequences 
stiffeners in a form of strips, subjected to uniform compression were considered. The linear (buckling) and nonlinear (postbuckling) behaviour of stability with using FEM and with experiment verification of the results were analysed. On the combined results, the following conclusions can be formulated:

1. The classical approach of fem to the analysis of post critical states with implemented a higher form of buckling is incompatible with the real behavior of the structure.

2. In the fem model the higher buckling form in the post critical range is stable and staid, while in the physical model of the structure appears a jump to lowest form of buckling (on the lower energetic level).

3. The jump to the lowest form of buckling in the physical model is due to the high difference in the internal energy levels of the structure between the lowest and implemented the higher form of buckling.

4. The plates concept with longitudinal reinforcements arranged asymmetrically to the plates plane and made of isotropic material, which was used, allows to get a natural, the lowest flexural-torsional form of buckling.

5 The posbuckling equilibrium paths for the real structure and the numerical model with the reinforcements, retain the staid character, confirming the validity of the adopted in the numerical calculation the plate model of construction, enabling the description of the nonlinear stability issue.

6. The above indicates the possibility of extending further studies on the research of structures damage process by experiment and numerical calculations.

\section{REFERENCES}

1. Bazant ZP, Cedolin L. Stability of structures. Elastic, inelastic, fracture and damage theories. Oxford University Press, 1991.

2. Czapski P., Kubiak T. Influence of fibre arrangement on the buckling load of composite platesanalytical solution. Fibres and Textiles in Eastern Europe, 113(5), 2015, 92-98.

3. Dębski H., Experimental investigation post-buckling behaviour of composite column with top-hat cross section. Eksploatacja i Niezawodnosc Maintenance and Reliability, 2, 2013, 105-109.
4. Debski, H.; Sadowski, T. Modelling of microcracks initiation and evolution along interfaces of the $\mathrm{WC} /$ Co composite by the finite element method. Computational Materials Science, 83, 2014, 403-411.

5. Falkowicz, K., Ferdynus, M., Dębski, H. Numerical analysis of compressed plates with a cut-out operating in the geometrically nonlinear range. Eksploatacja i Niezawodnosc-Maintenance And Reliability, 17(12), 2015, 222-235..

6. Falkowicz K., Mazurek P., Różyło P., Wysmulski P., Smagowski W. Experimental and nu-merical analysis of the compression thin-walled composite plate. Advances In Science And Technology Research Journal, 31(10), 2016, 177-184.

7. Falkowicz K., Ferdynus M., Wysmulski P. FEM analysis of critical loads plate with cut-out. Applied Computer Science, 2(11), 2015, 43-49.

8. Falkowicz K., Ferdynus M., Dębski H. Numerical analysis of compressed plates with a cut-out operating in the geometrically nonlinear range. Eksploatacja i Niezawodnosc-Maintenance And Reliability, 2(17), 2015, 222-227.

9. Jain P., Kumar A. Postbuckling response of square laminates with a central circular cutout. Composite Structures, 65, 2004, 179-185.

10. Klepka, T.; Debski, H.; Rydarowski, H. Characteristics of high-density polyethylene and its properties simulation with use of finite element method. Polimery, 54(9), 2009, 668-672.

11. Koiter WT. Elastic stability and post-buckling behavior. In Proceedings of the Symposium on Nonlinear Problems. Wisconsin: Univ. of Wisconsin Press, 1963, 257-275.

12. Kołakowski Z., Kowal-Michalska K., editors. Selected problems of instabilities in composite structures - a series of monographs, Technical University of Lodz Press, 1999.

13. Kopecki T. Numerical and experimental analysis of post-critical deformation states in a tensioned plate weakned by a crack. Journal of Theoretical and Applied Mechanics, 48(1), 2010, 45-70.

14. Kubiak T. Static and Dynamic Buckling of ThinWalled Plate Structures. Springer, 2013, 1-25, http://dx.doi.org/10.1007/978-3-319-006543_1, http://dx.doi.org/10.1007/978-3-31900654-3.

15. Kumar D., Singh S.B. Effects of boundary conditions on buckling and postbuckling responses of composite laminate with various shaped cutouts. Composites Structures, 92, 2010, 769-779.

16. Krolak M., Mania R. Statics, dynamics and stability of structures. Stability of thin-walled plate structures. Series of monographs. Łodz: Technical University of Lodz, 2011.

17. Lonkwic P., Różyło P. Theoretical and experimental analysis of loading impact from the progressive gear on the lift braking distance with the use of the 
free fall method. Advances in Sci-ence and Technology Research Journal, 10(30), 2016, 103-109.

18. Prabhakara D.L., Datta P.K. Vibration, Buckling and Parametric Instability Behaviour of Plates with Centrally Located Cutouts Subjected to In-Plane Edge Loading (Tension or Compression). ThinWalled Structures, 27(4), 1997, 287-310.

19. Ritchie D., Rhodes J. Buckling and post-buckling behaviour of plates with holes. The Aeronautical Quarterly, 26(4), 1975, 281-296.

20. Rozylo P. Optimization of I-section profile design by the finite element method. Advances in Science and Technology Research Journal, 10(29), 2016, 52-56.

21. Rozylo P., Wrzesinska K. Numerical analysis of the behavior of compressed thin-walled elements with holes. Advances in Science and Technology Research Journal 10(31), 2016, 199-206.

22. Rudawska, A.,Debski, H. Experimental And Numerical Analysis Of Adhesively Bonded Aluminium Alloy Sheets Joints. Eksploatacja i Niezawodnosc - Maintenance and Reliability 1, 2011, 4-10.

23. Shah A.A, Ribakov Y. Recent trends in steel fibered hihg-strenght concrete. Mater Des 32, 2011, 4122-51.

24. Shanmugam N.E. Openings in Thin-walled Steel
Structures. Thin-Walled Structures, 28(3/4), 1997, 355-372.

25. Singer J, Arbocz J., Weller T. Buckling experiments. Experimental methods in buckling of thin-walled structure. Basic concepts, columns, beams, and plates. New York: John Wiley \& Sons inc., 1998.

26. Singer J., Arbocz J., Weller T., Buckling experiments. experimental methods in buckling of thinwalled structure. Shells built-up structures, composites and additional topics. New York: John Wiley \& Sons inc., 2002.

27. Spencer H., Walker A.. Techniques for Measuring The critical Loads of column and Plates. SeSa Spring Meeting, 25, 1974.

28. Tereszkowski Z. An experimental method for determining critical loads of plates. Archive of mechanical engineering, 3, 1970, 485-493.

29. Timoshenko S., Woinowsky-Krieger S. Theory of plates and shells. McGraw-Hill, New York, 1959.

30. Wysmulski P., Dębski H., Różyło P., Falkowicz K. A study of stability and post-critical behaviour of thinwalled composite profiles under compression. Eksploatacja i Niezawodnosc-Maintenance And Reliability 4(18), 2016, 632-637. 